\title{
Cost Forecasting Analysis on Bored and Cast-In-situ Piles in Sri Lanka: Case Study at Selected Pile Construction Sites in Colombo Metropolis Area
}

\author{
S. Surenth, R.M.P.P.V. Rajapakshe, I.S. Muthumala and M.N.C. Samarawickrama
}

\begin{abstract}
Installation of bored and cast-in-situ (CIB) piles is a complicated process and relates to a large number of factors connected with subsurface uncertainties, contractor experience and sitespecific factors. Such factors make it difficult for the estimator to predict the cost of a CIB pile in the tendering stage. This study was carried out to identify most influential factors on cost of CIB pile construction with relevance to local conditions and to develop a cost prediction criterion for CIB construction in Sri Lanka. It was initiated with a study on cost influential factors and estimation models developed in the international context. Then the study proceeded to identify additional specific factors relevant to the local conditions using a questionnaire survey and analysis. Cost prediction models were then developed for local context using regression analysis based on the identified most influential factors, and finally, developed models were validated using actual cost data. It was revealed that the most critical cost affecting factors are pile size, pile drilling time, depth of pile, concrete pouring time, rock socket length, drilling type and weather conditions. Linear cost models developed for each of these factors were amalgamated to one overall cost prediction model. This was found to be successful during the validation with actual costs of executed piling projects. Moreover, it is recommended to be used along with the intuitive judgment of the decision maker and the model should be timely readjusted with updated market rates at least in three-month periods.
\end{abstract}

Keywords: $\quad$ Pile foundations; Bored piles construction; Cost of pile

\section{Introduction}

Pile construction is a comparatively complicated process, which initiates with geotechnical investigations, from which insufficient or inaccurate data collection causes unforeseen delays and cost variations during the pile installation. Cast-in-situ bored piles are preferred over other deep foundation options due its inherent cost effectiveness in construction (Mullins and Winters [1]). During the pile boring, problems associated with pile drilling and disposal of excavated material cause heavy influence on the site performance (Zayed [2]). In addition, rate of reinforcement gauge installation and concrete pouring also affect the pile construction economy. To optimize the profit margins, while maintaining the required quality standards, planners should be able to forecast the level of influence of such factors on cost of piles at the tendering and planning stages.

However, such forecasting is mostly based on the previous experience of the team. Even though substantial amount of studies has been carried out in the international context, none has been reported in Sri Lanka about pile construction economy and instead studies have only been focused on pile design aspects. Furthermore, even planners are reluctant in applying such forecasting models due to lack of confidence on the applicability of such factors or cost prediction models to local context as these factors will need to be verified and appreciate methodically before application.

This study was carried out to reduce this gap to some extent and to form a base for further studies for more accurate cost prediction models for local context.

\footnotetext{
Eng. S. Surenth, AMIE(SL), MITP(SL), BSc. Plnr.Hons. (Moratuwa), BTec. Eng.Hons. (OUSL), Dip.in.PM (LBS),

Construction Engineer, CHEC Port City Colombo (Pvt)

Ltd., Sri Lanka. Email:surenthonline@gmail.com

ORCID ID: https://orcid.org/0000-0001-9172-1273

R.M.P.P.V. Rajapakshe, NDES.Civil. (TTI), Technical officer, Western Province Engineering Organization, Sri Lanka.Email:prabathor@gmail.com

I.S. Muthumala, BTec. Eng.Hons (OUSL), Civil Superintendent, State Engineering Corporation, Sri Lanka. Email:isharashamika@gmail.com

Eng. M.N.C. Samarawickrama, CEng., MIE(SL), MGS (SL), BSc. Eng.Hons. (Moratuwa), MSc. (Peradeniya), MBA (Moratuwa), Senior Lecturer in Civil Engineering, Department of Civil Engineering, The Open University of Sri Lanka. Email:mahesh.samarawickrama@gmail.com ORCID ID: https://orcid.org/0000-0002-5378-764X
} 
This study was carried out to achieve following objectives.

- Identify the cost influential factors in bored and Cast-in-situ (CIB) pile construction.

- Determine the locally most relevant cost influential factors and impact of these on the cost of a CIB pile.

- Develop cost prediction models which can be effectively used in the planning/tendering stages of local CIB piling projects.

\section{Previous Studies}

Peurifoy et al. [3] have identified the following cost influential factors in CIB pile construction.

- $\quad$ Soil type (i.e. sand, clay, stiff clay, etc).

- Drill type.

- Method of spoil removal.

- Pile axis adjustment.

- Equipment operator efficiency.

- Weather conditions.

- Concrete pouring method and efficiency.

- Waiting time for other operations (i.e. pile axis adjustment).

- Job and management conditions and

- Cycle time.

Lowe et al. [4] describe the development of linear regression models to predict the construction cost of buildings, based on data collected from 286 sites in the United Kingdom. Moreover, they have identified that raw cost can be rejected as a suitable dependent variable and models have been developed for cost $/ \mathrm{m}^{2}$, $\log$ of cost, and $\log$ of cost $/ \mathrm{m}^{2}$. Both forward and backward stepwise analyses have been performed, resulting in a total of six models. Forty-one potential independent variables have been identified in the study and five variables appeared in each of the six models were gross internal floor area (GIFA), functionality, duration, mechanical installations and piling, suggesting that these are the key linear cost drivers in construction projects.

Zayed and Halpin [5] have reported that regression technique can be effectively used to assess piling process productivity, cycle time, and cost. Fifty-two models have been developed to assess these factors. These models were validated to assure the accuracy. The concept of the validation factor (VF) was introduced to check the level of fit between the proposed models and actual production levels. In their study they have achieved a VF of $95 \%$ fit for more than $52 \%$ of the model outputs and a $90 \%$ fit for $83 \%$ of the models.

Zayed [6] has developed an Artificial Neural Network (ANN) technique to assess the pilling process productivity, cycle time and cost. The ANN includes seven neurons in the input layer: three soil types; two construction methods; pile depth; and auger height. The piling process outputs contain cycle time, productivity and cost. Cycle time is composed of drilling, cage erection, funnel erection, tremie erection, axis adjustment, pouring and machine relocation times. Cost involves total and drilling costs where total cost is the cost that covers the whole process of constructing a pile (drilled shaft). Adding these variables yields to ten outputs: seven cycle time activities; two cost items; and productivity, to represent the pilling process efficiently. Consequently, $90 \%$ of the output variables have been predicted with more than $75 \%$ fitness in the level of fairly good to acceptable range.

\section{Methodology}

The study was initiated with a detailed review on previous studies carried out internationally to identify the cost influential factors in CIB pile construction.

After initial identification of general cost influential factors, additional locally most relevant factors were identified with a questionnaire survey analysis using statistical techniques. This was performed among contractors, consultants and other relevant staff in pile construction industry. Further, statistical analyses were performed on finalized cost influential factors to develop cost prediction models and described in Sections 3.1 to 3.3.

\subsection{Questionnaire Survey Approach}

A descriptive questionnaire survey was conducted among staff representing all levels in the pile construction industry hierarchy, who are specialists in concrete cast in-situ bored pile design and construction to obtain their views and responses in identifying the critical factors that affect the cost of pile construction projects. At the initial stage, a preliminary questionnaire survey was conducted to identify the locally relevant factors in addition to the factors identified in the literature review. The questionnaire was divided into two sections, viz., open type questions to encourage the respondent to provide free responses (Nauom [7]) and closed type questions to get 
straightforward feedback (Neter et al. [8]) with quick answers by short responses in the form of ranking. Respondents were asked to provide information based on their experience and simultaneously obtained actual financial figures of typical piling projects.

For the questionnaire, 120 responses were received. Sixty four percent $(64 \%)$ of pilling contractors expressed their willingness to comment and help on this task. However, the number of replies were limited to $35.4 \%$ out of initially committed contractors, which yields to a data representation of $22 \%$ of total piling contractor population. This level is satisfactory enough to arrive at a reasonable level of conclusions at this stage.

\subsection{Identifying the Influential Level on Cost}

A three scale Likert scale was employed to analyse the influential level of qualitative cost affecting factors. Weightage and rating for the questionnaire for each parameter was assigned according to "Average Index" formula proposed by Majid [9].

Average Index $(A I)=\frac{\sum(\delta \times n)}{N}$

$\mathrm{n}$ - frequency of the respondents

$\mathrm{N}$ - total number of respondents

$\delta$ - corresponding weightage

Weightage was assigned as per Table 1.

Table 1 - Weightage table

\begin{tabular}{|c|c|}
\hline Ranking by respondent & $\begin{array}{c}\text { Corresponding } \\
\text { weight }(\boldsymbol{\delta})\end{array}$ \\
\hline 1 & 3 \\
\hline 2 & 2 \\
\hline 3 & 1 \\
\hline
\end{tabular}

Rating scale was employed as per below given criteria.

Less importance $(1.00<$ Average Index $<1.5)$

Average Importance $(1.5<$ Average Index $<2.5)$ High Importance $(2.5<$ Average Index $<3.5)$

Level of importance can be estimated from equation no.2 proposed by (Majid [9]).

\section{Level of importance (\%)}

$$
=\frac{\text { Average Index }}{6} \times 100
$$

\subsection{Development of Cost Model}

Two-fold regression analyses were performed in the overall analysis of all the projects (where data are available) and a matrix type analysis was conducted over individual as well as overall project databases. Totally, 3,702 piles were used for the analysis representing 32 construction projects. Details of no. of samples are shown in Figure 2. The regression models were built using a two-phase framework as shown in Figure 1.

i. The first phase included model building that can be summarized as:

a. Collect quantitative and qualitative data and select model variables,

b. Check the significance of model variables based on statistical criteria, and

c. Develop the regression model.

ii. In the second phase, developed regression models were improved using an iterative approach, until a substantial match between actual and predicted data is achieved.

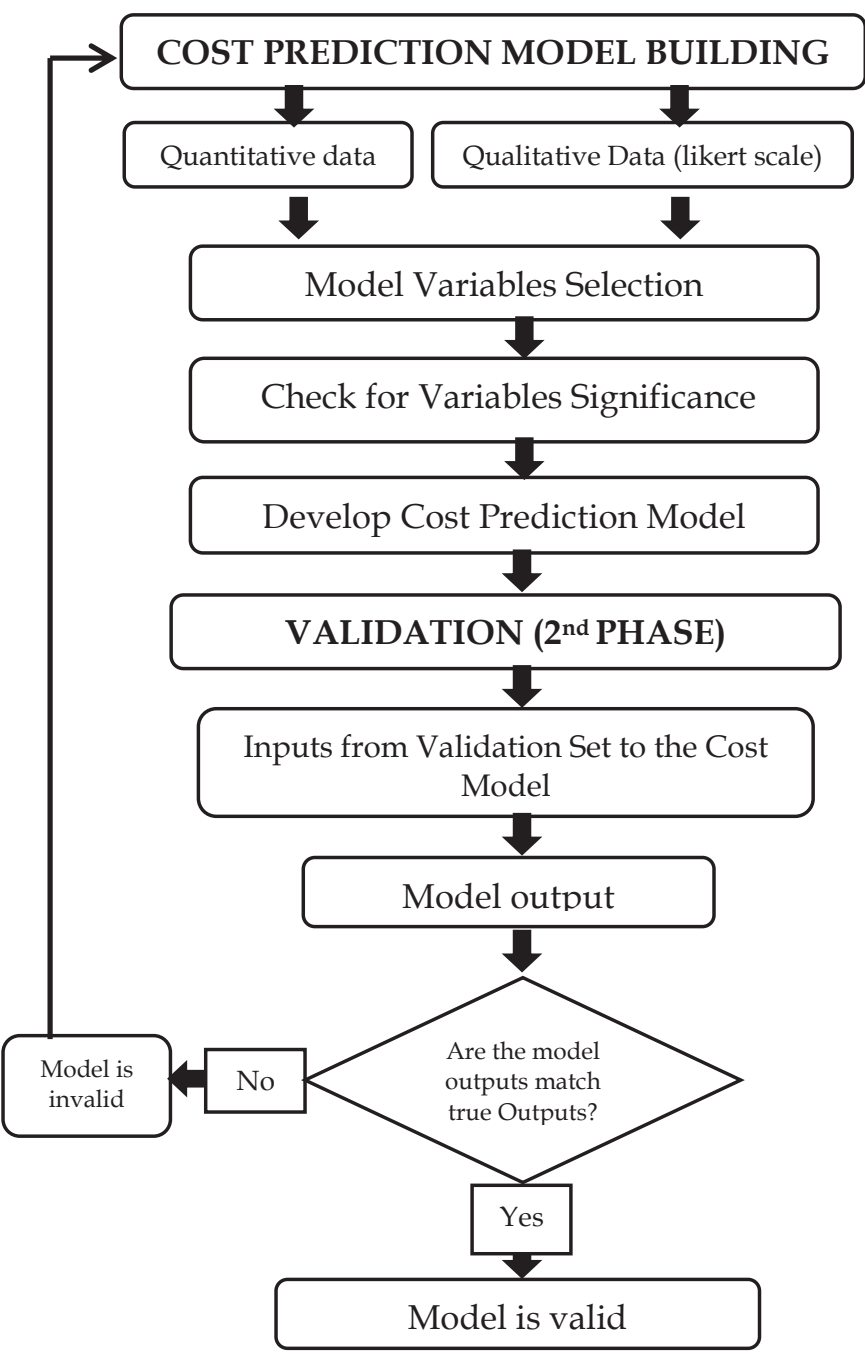

Figure 1 - Cost model frameworks for CIB pile construction 


\subsubsection{Model Design for Overall Cost}

Multiple regression analysis specified by the following model was used to predict the cost.

$$
\begin{array}{r}
\text { Cost }=\beta_{0}+\beta_{1} X_{1}+\beta_{2} X_{2}+\beta_{3} X_{3}+\cdots+\beta_{n} X_{n} \\
\ldots(3) \\
\text { Cost }=\beta_{0}+\sum_{n=1}^{\infty}\left(\beta_{n} X_{n}\right)
\end{array}
$$

$\beta=$ Coefficient of the particular factor affecting piling cost

$X_{n}=$ Pile performance factor

\subsubsection{Performance Variable Attribute Matrix}

As mentioned in Section 2, a large number of variables affect the pile construction economy. In order to develop a more simplified and accurate pile cost prediction model, locally most influential factors have been identified for this analysis, based on the outcomes of 3.1 and 3.2, viz., pile size, soil type, pile depth, drilling type and rock socket length as given in Table 2 . The pile diameter $(\varphi)$ varied from $600 \mathrm{~mm}$ to $1800 \mathrm{~mm}$, categorized as small $(<800 \mathrm{~mm})$, medium $(800 \mathrm{~m}-1200 \mathrm{~mm})$ and large $(>1200$ $\mathrm{mm})$. Soil types were categorized as peat, transported and residual. Based on secondary data, the depth of piles (depth down to bedrock level) was categorized as D1 $(<15 \mathrm{~m})$, D2 (15 m-23 m), D3 (23 m - $30 \mathrm{~m})$ and D4 (>30 m). Considering the drilling (boring) method, it has been identified that only rotary and hydraulic rig type boring machines are mostly employed locally. Hence, above gives rise to five variables with sixteen variable-attributes.

Then, the collected data were divided into several data sets with the selected variables and their attributes. Data were divided into three main sets based on pile size, one set for each size. Each data set was then categorized based on soil type, Pile size and drilling type attributes and those are proceeded with the other variables such as pile depth, rock socket length and drilling (boring) type to derived the cost estimation equation.

The MINITAP statistical software was used to develop all the statistical models and these guarantee that the model best fits the data. Two different criteria were used to test the models, such as coefficient of determination $\mathrm{R}^{2}$ and $\mathrm{p}$ value to validate the fitness. Eighteen different case models were developed for different variables as explained above. For example, Figure 2 shows the simulation matrix pattern for a smaller diameter pile in peat soil condition with rotary boring method.

\begin{tabular}{|c|c|c|c|c|c|}
\hline & & \multicolumn{4}{|c|}{ Variable-Attributes } \\
\hline \multirow{5}{*}{$\frac{\frac{\mathscr{Q}}{0}}{\frac{\pi}{\pi}}$} & Pile size (dia.) (mm) & Small $(<800)$ & Medium (800-1200) & Large $(>1200)$ & \\
\hline & Soil type & Peat & Transported & Residual & \\
\hline & $\begin{array}{l}\text { Pile depth (down to } \\
\text { bedrock) (avg.) (m) }\end{array}$ & $\begin{array}{l}\text { Less than } 15 \\
\text { (D1) }\end{array}$ & $15-23(\mathrm{D} 2)$ & 23-30 (D3) & $\begin{array}{l}\text { Beyond } 30 \\
\text { (D4) }\end{array}$ \\
\hline & Drilling type & Rotary & Hydraulic rig & & \\
\hline & Rock socket length (m) & 1 & $1-2$ & $2-3$ & More than 3 \\
\hline
\end{tabular}

Table 2 - Pile cost performance variable attributes matrix 


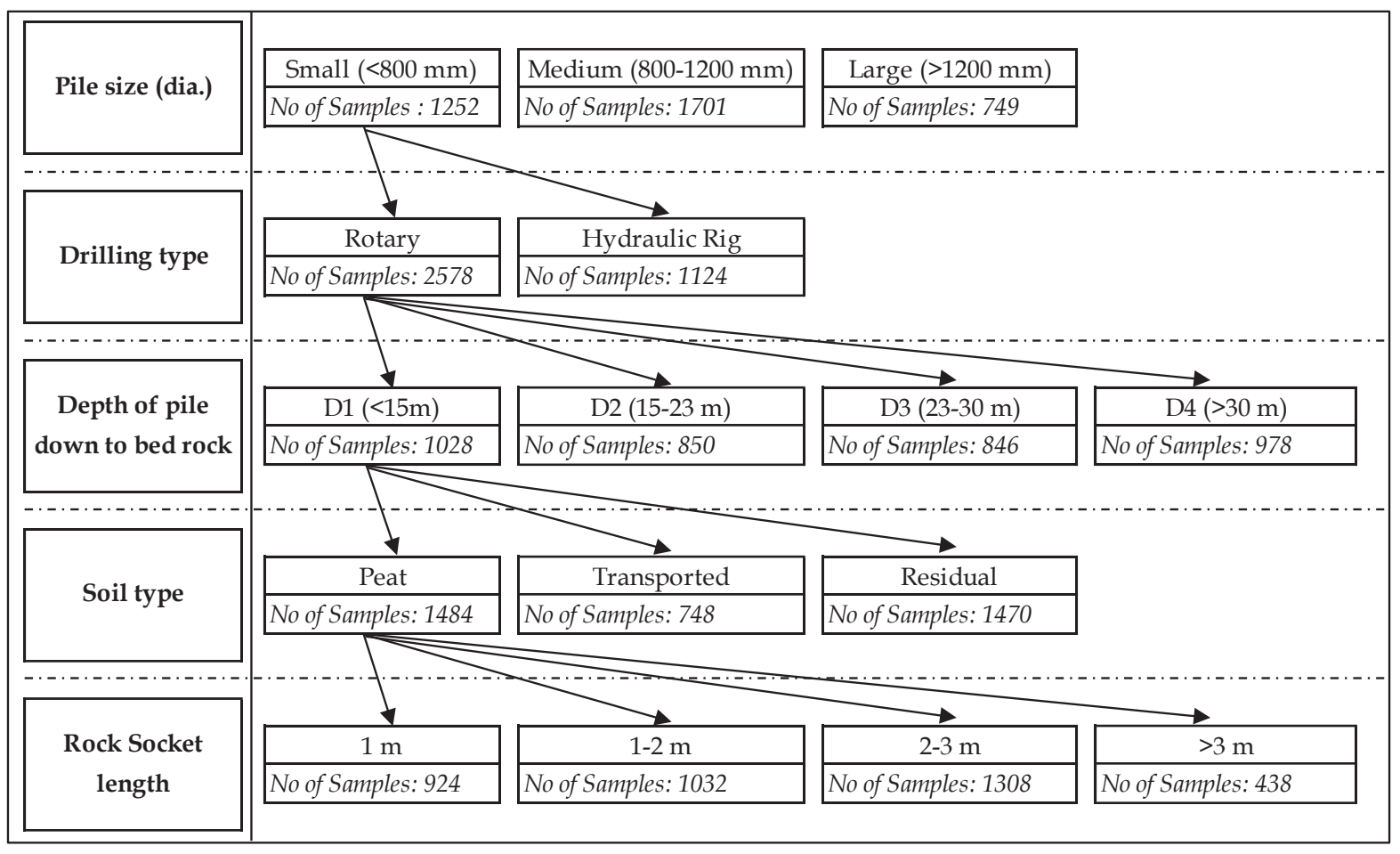

Figure 2 - Simulation input data for small pile size with sample sizes

\subsubsection{Validation of Regression Models}

The validation of models was performed by comparing the outputs of developed models with actual cost data collected from pile construction sites, which are completely different from the data used for iterative model improvement process. If the model results substantially matched actual pile cost figures, then the models were concluded as valid and may be used in actual construction practice. The validation was carried out for all developed models. The level of validation was estimated using the validation factor (VF), given by:

\section{Validation Factor $(\boldsymbol{V} F)$}

$$
=\frac{\text { Cost Prediction Model Result (PMR) }}{\text { Collected Actual Cost (CAC) }}
$$

Table 4 shows the calculated VF for peat, transported and residual soils, using rotary and hydraulic rig drilling methods. This table shows that the VF for smaller pile $(<800 \mathrm{~mm})$ in peat soil with $<15 \mathrm{~m}$ depth and $1 \mathrm{~m}$ rock socket, drilled with rotary drilling method is 0.95 while it is 0.85 for $1-2 \mathrm{~m}$ rock socket. This indicates that the model for the $1 \mathrm{~m}$ rock socket substantially matches the actual field data.

\section{Results and Analysis}

Based on the previous studies done on the construction process, the following factors were identified as the most influential factors on pile construction productivity; i. Soil type (i.e. Peat, Transported, Residual);

ii. Construction methods (drilling type and concrete pouring method);

iii. Pile depth (down to bedrock depth and rock socket length);

iv. Cycle time (drilling and cage erection, funnel erection, tremie erection, axis adjustment, pouring and machine relocation time);

v. Method of spoil removal;

vi. Equipment operator efficiency;

vii. Weather conditions; and

viii. Job and management conditions.

Above identified factors were verified and prioritized through preliminary questionnaires and interviews as mentioned in Section 3.1. Through these preliminary questionnaires, the following additional factors were identified in the local context:

i. Adequate geotechnical data (i.e. bore hole availability);

ii. Actual piling project completion period; and

iii. Pile size.

Figure 3 depicts the results of the ranking on influence level on cost and it can be concluded that the pile size, soil type, weather condition and drilling type have been identified as high impact factors on cost performance of pile construction. Moreover, other factors have been reached above $40 \%$ in influential level and can be considered as substantially high impact 
factors on the pile cost. Hence, the nine identified factors were selected as high impact factors on cost performance of CIB piles which are graphically illustrated (red colour bars) in Figure 3.

However, due to lack of field data, weather condition and geotechnical data have been taken off from further evaluation of the nine identified factors list. Furthermore, soil type factor had to be ignored in the overall cost prediction model, but it was considered in the development of case regression models. Consequently, only six factors were selected to carry out the regression analysis to proceed in the development of the overall cost prediction model.

Overall regression analysis on identified factors revealed that the cost of pile is positively and significantly related to pile size, drilling time, concrete pouring time, depth of pile down to bedrock and rock socketing is negatively and significantly related to the type of drilling.

Moreover, a coefficient of determination, $\mathrm{R}^{2}=89.93$ (which means that $89 \%$ of the piling cost variable can be explained by the independent variables), was able to reach with identified independent variables. The overall cost prediction model can be expressed as follows.

$$
\begin{aligned}
\text { Overall Cost }= & -1,234,574+1,366.9 X_{1}+87.7 X_{2} \\
& +29,309 X_{3}+75,060 X_{4}+72.5 X_{5} \\
& -15,302 X_{6}
\end{aligned}
$$

$\mathrm{X}_{1}=$ Pile size $(\mathrm{mm})$

$\mathrm{X}_{2}, \mathrm{X}_{5}=$ Cycle time (sec) [Drilling time $\left(\mathrm{X}_{2}\right)$ and

Concrete pouring time $\left.\left(\mathrm{X}_{5}\right)\right]$

$X_{3}=$ Depth of pile down to bedrock (m)

$\mathrm{X}_{4}=$ Rock socket length $(\mathrm{m})$

$\mathrm{X}_{6}=$ Drilling type (rotary, hydraulic rig)

Case models (matrix models) which have been developed for specific drilling type, pile size and the soil type represent the pile cost against depth of pile down to bedrock and rock socketing. Interaction between pile depth and rock socketing were checked to determine whether it is statistically valid to be embedded in the model. This interaction met the criteria to be included in the respective pile cost models.

Statistical validity of the regression models was checked with p-value $(\mathrm{P})$, which has been revealed to be valid and coefficient of determination (R2) (which reached more than $80 \%$ ). These models are given in Table 3 . Hence it can be concluded that these models can be used in different cases to estimate the cost in the tendering stage of the projects. The regression matrix analysis was derived for 18 matrix patterns to estimates cost with the response of particular case description as mentioned in Table 3.

Results from individually carried out analysis for the models show that each model is valid and determination of coefficient values are above $80 \%$. Hence, it is implied that data vary little around the fitted models.

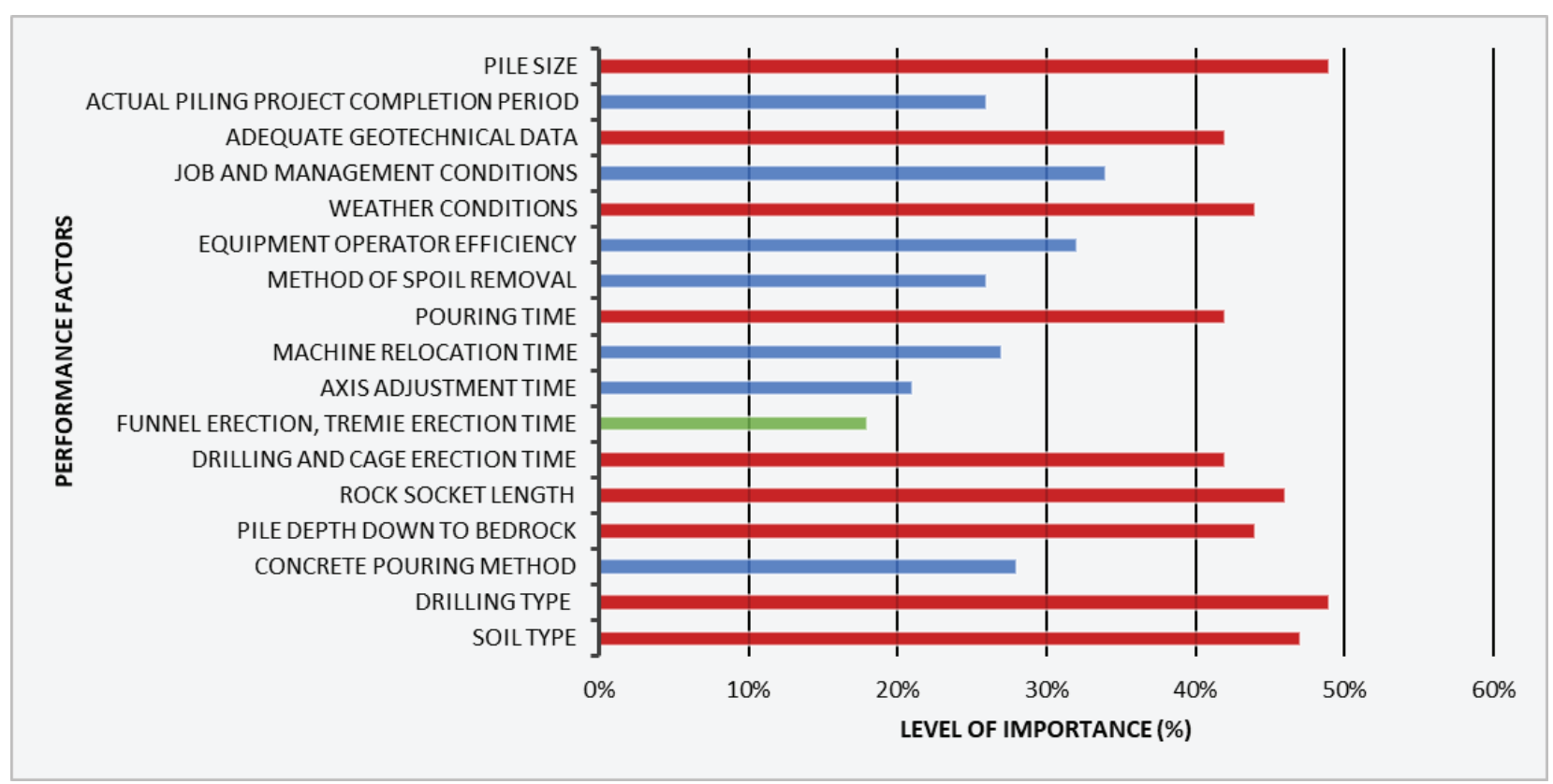

Figure 3 - Importance level of factors on cost of pile construction 
Table 3 - Pile cost performance models

\begin{tabular}{|c|c|c|c|c|c|c|c|}
\hline No & Case description & \multicolumn{6}{|c|}{ Performance model } \\
\hline 1 & Rotary-Small-Peat & Cost (Rs.) = & $-387,482$ & $\begin{array}{l}+508 \\
\text { Drilling time }\end{array}$ & $\begin{array}{l}+23,233 \\
\text { Depth of pile }\end{array}$ & $\begin{array}{l}\text { - 25,764 Rock } \\
\text { socket length }\end{array}$ & $\begin{array}{l}+1,147 \text { Concrete } \\
\text { pouring time }\end{array}$ \\
\hline 2 & $\begin{array}{l}\text { Rotary-Small- } \\
\text { Residual }\end{array}$ & Cost (Rs.) $=$ & $-518,016$ & $\begin{array}{l}-162 \text { Drilling } \\
\text { time }\end{array}$ & $\begin{array}{l}+31,400 \\
\text { Depth of pile }\end{array}$ & $\begin{array}{l}\text { +99,476 Rock } \\
\text { socket length }\end{array}$ & $\begin{array}{l}+2,057 \text { Concrete } \\
\text { pouring time }\end{array}$ \\
\hline 3 & $\begin{array}{l}\text { Rotary-Small - } \\
\text { Transported }\end{array}$ & Cost (Rs.) $=$ & -543 & $\begin{array}{l}\text { + Drilling } \\
\text { time }\end{array}$ & $\begin{array}{l}\text { +321 Depth } \\
\text { of pile }\end{array}$ & $\begin{array}{l}\text { + Rock socket } \\
\text { length }\end{array}$ & $\begin{array}{l}+ \text { Concrete } \\
\text { pouring time }\end{array}$ \\
\hline 4 & $\begin{array}{l}\text { Hydraulic rig-Small- } \\
\text { Peat }\end{array}$ & Cost (Rs.) $=$ & $-323,063$ & $\begin{array}{l}+628 \\
\text { Drilling time }\end{array}$ & $\begin{array}{l}+27,861 \\
\text { Depth of pile }\end{array}$ & $\begin{array}{l}\text { - 64,795 Rock } \\
\text { socket length }\end{array}$ & $\begin{array}{l}+265 \text { Concrete } \\
\text { pouring time }\end{array}$ \\
\hline 5 & $\begin{array}{l}\text { Hydraulic rig-Small- } \\
\text { Residual }\end{array}$ & Cost (Rs.) $=$ & $-417,455$ & $\begin{array}{l}\text { - } 42 \text { Drilling } \\
\text { time }\end{array}$ & $\begin{array}{l}+41,358 \\
\text { Depth of pile }\end{array}$ & $\begin{array}{l}+2,613 \text { Rock } \\
\text { socket length }\end{array}$ & $\begin{array}{l}+323 \text { Concrete } \\
\text { pouring time }\end{array}$ \\
\hline 6 & $\begin{array}{l}\text { Hydraulic rig-Small- } \\
\text { Transported }\end{array}$ & Cost (Rs.) $=$ & 61,386 & $\begin{array}{l}+728 \\
\text { Drilling time }\end{array}$ & $\begin{array}{l}+25,723 \\
\text { Depth of pile }\end{array}$ & $\begin{array}{l}\text { - 188,839 Rock } \\
\text { socket length }\end{array}$ & $\begin{array}{l}+931 \text { Concrete } \\
\text { pouring time }\end{array}$ \\
\hline 7 & Rotary-Medium-Peat & Cost (Rs.) $=$ & $-1,013,582$ & $\begin{array}{l}+1,149 \\
\text { Drilling time }\end{array}$ & $\begin{array}{l}-20,845 \\
\text { Depth of pile }\end{array}$ & $\begin{array}{l}\text { +102,930 Rock } \\
\text { socket length }\end{array}$ & $\begin{array}{l}+9,236 \text { Concrete } \\
\text { pouring time }\end{array}$ \\
\hline 8 & $\begin{array}{l}\text { Rotary-Medium- } \\
\text { Residual }\end{array}$ & Cost (Rs.) $=$ & $-548,009$ & $\begin{array}{l}+508 \\
\text { Drilling time }\end{array}$ & $\begin{array}{l}+81,856 \\
\text { Depth of pile }\end{array}$ & $\begin{array}{l}\text { - 145,490 Rock } \\
\text { socket length }\end{array}$ & $\begin{array}{l}+531 \text { Concrete } \\
\text { pouring time }\end{array}$ \\
\hline 9 & $\begin{array}{l}\text { Rotary-Medium- } \\
\text { Transported }\end{array}$ & Cost (Rs.) = & $-174,973$ & $\begin{array}{l}-115 \text { Drilling } \\
\text { time }\end{array}$ & $\begin{array}{l}+71,959 \\
\text { Depth of pile }\end{array}$ & $\begin{array}{l}\text { + 58,612 Rock } \\
\text { socket length }\end{array}$ & $\begin{array}{l}+352 \text { Concrete } \\
\text { pouring time }\end{array}$ \\
\hline 10 & $\begin{array}{l}\text { Hydraulic rig- } \\
\text { Medium-Peat }\end{array}$ & Cost (Rs.) $=$ & $-1,118,021$ & $\begin{array}{l}+373 \\
\text { Drilling time }\end{array}$ & $\begin{array}{l}+55,137 \\
\text { Depth of pile }\end{array}$ & $\begin{array}{l}\text { + 316,501 Rock } \\
\text { socket length }\end{array}$ & $\begin{array}{l}\text { - } 305 \text { Concrete } \\
\text { pouring time }\end{array}$ \\
\hline 11 & $\begin{array}{l}\text { Hydraulic rig- } \\
\text { Medium-Residual }\end{array}$ & Cost (Rs.) = & $3,098,072$ & $\begin{array}{l}+139 \\
\text { Drilling time }\end{array}$ & $\begin{array}{l}+59,402 \\
\text { Depth of pile }\end{array}$ & $\begin{array}{l}\text { - 1,118,444 Rock } \\
\text { socket length }\end{array}$ & $\begin{array}{l}+826 \text { Concrete } \\
\text { pouring time }\end{array}$ \\
\hline 12 & $\begin{array}{l}\text { Hydraulic rig- } \\
\text { Medium-Transported }\end{array}$ & Cost (Rs.) $=$ & 509,465 & $\begin{array}{l}\text { - } 138 \text { Drilling } \\
\text { time }\end{array}$ & $\begin{array}{l}+54,188 \\
\text { Depth of pile }\end{array}$ & $\begin{array}{l}\text { - 50,900 Rock } \\
\text { socket length }\end{array}$ & $\begin{array}{l}+782 \text { Concrete } \\
\text { pouring time }\end{array}$ \\
\hline 13 & Rotary-Large-Peat & Cost (Rs.) $=$ & $12,288,358$ & $\begin{array}{l}+60 \text { Drilling } \\
\text { time }\end{array}$ & $\begin{array}{l}+65,114 \\
\text { Depth of pile }\end{array}$ & $\begin{array}{l}\text { - 3,934,108 Rock } \\
\text { socket length }\end{array}$ & $\begin{array}{l}\text { - } 68 \text { Concrete } \\
\text { pouring time }\end{array}$ \\
\hline 14 & $\begin{array}{l}\text { Rotary-Large- } \\
\text { Residual }\end{array}$ & Cost (Rs.) $=$ & 570,318 & $\begin{array}{l}\text { - } 126 \text { Drilling } \\
\text { time }\end{array}$ & $\begin{array}{l}+94,166 \\
\text { Depth of pile }\end{array}$ & $\begin{array}{l}\text { - 187,845 Rock } \\
\text { socket length }\end{array}$ & $\begin{array}{l}\text { - } 368 \text { Concrete } \\
\text { pouring time }\end{array}$ \\
\hline 15 & $\begin{array}{l}\text { Rotary-Large- } \\
\text { Transported }\end{array}$ & Cost (Rs.) $=$ & $1,247,232$ & $\begin{array}{l}+61 \text { Drilling } \\
\text { time }\end{array}$ & $\begin{array}{l}+91,524 \\
\text { Depth of pile }\end{array}$ & $\begin{array}{l}\text { - 307,532 Rock } \\
\text { socket length }\end{array}$ & $\begin{array}{l}+61 \text { Concrete } \\
\text { pouring time }\end{array}$ \\
\hline 16 & $\begin{array}{l}\text { Hydraulic rig-Large- } \\
\text { Peat }\end{array}$ & Cost (Rs.) $=$ & $1,946,718$ & $\begin{array}{l}+32 \text { Drilling } \\
\text { time }\end{array}$ & $\begin{array}{l}+91,579 \\
\text { Depth of pile }\end{array}$ & $\begin{array}{l}\text { - 841,195 Rock } \\
\text { socket length }\end{array}$ & $\begin{array}{l}+4,020 \text { Concrete } \\
\text { pouring time }\end{array}$ \\
\hline 17 & $\begin{array}{l}\text { Hydraulic rig-Large- } \\
\text { Residual }\end{array}$ & Cost (Rs.) = & 696,443 & $\begin{array}{l}+17 \text { Drilling } \\
\text { time }\end{array}$ & $\begin{array}{l}+43,692 \\
\text { Depth of pile }\end{array}$ & $\begin{array}{l}\text { + 108,325 Rock } \\
\text { socket length }\end{array}$ & $\begin{array}{l}+214 \text { Concrete } \\
\text { pouring time }\end{array}$ \\
\hline 18 & $\begin{array}{l}\text { Hydraulic rig-Large- } \\
\text { Transported }\end{array}$ & Cost (Rs.) $=$ & 240,559 & $\begin{array}{l}\text { - } 309 \text { Drilling } \\
\text { time }\end{array}$ & $\begin{array}{l}+110,805 \\
\text { Depth of pile }\end{array}$ & $\begin{array}{l}\text { + 87,691 Rock } \\
\text { socket length }\end{array}$ & $\begin{array}{l}+216 \text { Concrete } \\
\text { pouring time }\end{array}$ \\
\hline
\end{tabular}

The concept of validation factor (VF) has been developed to check the degree to which the designed models reflect field data. VF calculation has been applied for both developed modes such as overall cost prediction model and case model (matrix pattern). Based on Table 4 (case model or matrix model), the value of $\mathrm{VF}$ for more than $72 \%$ of the model output exceeds $75 \%$. About $18 \%$ of the outputs have VF values in the range of $65-75 \%$ fitness while about $10 \%$ of them have VF in the range of $60-65 \%$ fitness. Consequently, $72 \%$ of the model outputs have been predicted with more than $75 \%$ validity, which is fairly good and acceptable.
Overall cost prediction model results also have to be validated and compared with actual data to ensure that the designed models are good enough for real construction practice use. The validation factor (VF) has been calculated for different pile sizes considering its corresponding cost prediction model result with actual cost of that particular project. Hence, Table 5 shows the calculated validation factor for small $(800 \mathrm{~mm}<)$, medium $(800-1200$ $\mathrm{mm})$, and large $(1200 \mathrm{~mm}>$ ) pile sizes using rotary and hydraulic rig methods for different soil types. For example, consider the Project-C (Table 5) where the actual cost of $600 \mathrm{~mm}$ dia. pile is Rs. 562,631.67 which includes the total cost of pile, but the estimated cost is Rs. $461,357.97$. 
Table 4 -Validation factors for smaller pile (Project-A)

\begin{tabular}{|c|c|c|c|c|c|c|c|c|}
\hline \multicolumn{9}{|c|}{ Construction method at various rock socket length } \\
\hline & \multicolumn{4}{|c|}{ Rotary } & \multicolumn{4}{|c|}{ Hydraulic rig } \\
\hline & \multicolumn{4}{|c|}{ VF for Peat soil } & \multicolumn{4}{|c|}{ VF for Peat soil } \\
\hline Rock socket length & $1 \mathrm{~m}$ & $1-2 \mathrm{~m}$ & $2-3 \mathrm{~m}$ & $>3 \mathrm{~m}$ & $1 \mathrm{~m}$ & $1-2 \mathrm{~m}$ & $2-3 \mathrm{~m}$ & $>3 \mathrm{~m}$ \\
\hline \multicolumn{9}{|c|}{ Pile Depth (down to bed rock) } \\
\hline$<15 \mathrm{~m}$ & 0.95 & 0.85 & 0.68 & 0.79 & 0.68 & 0.75 & 0.88 & 0.85 \\
\hline $15-23 \mathrm{~m}$ & 0.85 & 0.83 & 0.63 & 0.83 & 0.83 & 0.76 & 0.83 & 0.88 \\
\hline $23-30 \mathrm{~m}$ & 0.81 & 0.80 & 0.70 & 0.93 & 0.79 & 0.82 & 0.81 & 0.96 \\
\hline \multirow[t]{2}{*}{$>30 \mathrm{~m}$} & 0.80 & 0.81 & 0.85 & 0.90 & 0.83 & 0.85 & 0.87 & 0.99 \\
\hline & \multicolumn{4}{|c|}{ VF for Transported soil } & \multicolumn{4}{|c|}{ VF for Transported soil } \\
\hline$<15 \mathrm{~m}$ & 0.89 & 0.87 & 0.80 & 0.76 & 0.91 & 0.82 & 0.84 & 0.88 \\
\hline $15-23 \mathrm{~m}$ & 0.95 & 0.96 & 0.91 & 0.86 & 0.83 & 0.68 & 0.62 & 0.89 \\
\hline $23-30 \mathrm{~m}$ & 0.84 & 0.71 & 0.93 & 0.92 & 0.87 & 0.79 & 0.64 & 0.91 \\
\hline \multirow[t]{2}{*}{$>30 \mathrm{~m}$} & 0.83 & 0.74 & 0.80 & 0.95 & 0.93 & 0.85 & 0.86 & 0.90 \\
\hline & \multicolumn{4}{|c|}{ VF for Residual soil } & \multicolumn{4}{|c|}{ VF for Residual soil } \\
\hline$<15 \mathrm{~m}$ & 0.85 & 0.78 & 0.81 & 0.74 & 0.83 & 0.93 & 0.82 & 0.83 \\
\hline $15-23 \mathrm{~m}$ & 0.93 & 0.87 & 0.83 & 0.84 & 0.76 & 0.82 & 0.93 & 0.87 \\
\hline $23-30 \mathrm{~m}$ & 0.90 & 0.94 & 0.80 & 0.81 & 0.69 & 0.80 & 0.82 & 0.96 \\
\hline$>30 \mathrm{~m}$ & 0.82 & 0.81 & 0.93 & 0.86 & 0.77 & 0.88 & 0.75 & 0.80 \\
\hline
\end{tabular}

Table 5 -Validation factors for real project data

\begin{tabular}{|c|c|c|c|c|c|c|c|c|c|}
\hline \multirow{2}{*}{$\begin{array}{c}\text { Pile } \\
\text { Size } \\
\text { (dia.) }\end{array}$} & \multicolumn{3}{|c|}{ Project-A } & \multicolumn{3}{|c|}{ Project-B } & \multicolumn{3}{|c|}{ Project-C } \\
\hline & $\begin{array}{c}\text { Cost-Model } \\
\text { (Rs.) }\end{array}$ & $\begin{array}{l}\text { Cost-Actual } \\
\text { (Rs.) }\end{array}$ & VF & $\begin{array}{l}\text { Cost-Model } \\
\text { (Rs.) }\end{array}$ & $\begin{array}{l}\text { Cost-Actual } \\
\text { (Rs.) }\end{array}$ & VF & $\begin{array}{c}\text { Cost-Model } \\
\text { (Rs.) }\end{array}$ & $\begin{array}{l}\text { Cost-Actual } \\
\text { (Rs.) }\end{array}$ & VF \\
\hline $600 \mathrm{~mm}$ & $517,621.30$ & $608,966.20$ & 0.85 & $568,224.55$ & $757,632.70$ & 0.75 & $461,357.97$ & $562,631.67$ & 0.82 \\
\hline $750 \mathrm{~mm}$ & $602,702.47$ & $782,730.50$ & 0.77 & - & - & - & $526,293.35$ & $634,088.40$ & 0.83 \\
\hline $800 \mathrm{~mm}$ & - & - & - & $1,244,466.00$ & $1,944,478.00$ & 0.64 & $650,211.75$ & $730,575.00$ & 0.69 \\
\hline $900 \mathrm{~mm}$ & $1,373,105.75$ & $1,880,967.00$ & 0.73 & $1,905,780.00$ & $1,868,412.00$ & 1.02 & - & - & - \\
\hline $1000 \mathrm{~mm}$ & $2,112,265.18$ & $3,106,272.32$ & 0.68 & $1,844,909.25$ & $1,826,642.80$ & 1.01 & $1,556,000.00$ & $1,809,302.33$ & 0.86 \\
\hline $1200 \mathrm{~mm}$ & $2,236,452.00$ & $2,981,936.00$ & 0.75 & $2,603,113.00$ & $2,958,082.95$ & 0.88 & $2,207,548.88$ & $2,794,365.67$ & 0.79 \\
\hline $1500 \mathrm{~mm}$ & - & - & - & - & - & - & $2,499,909.56$ & $3,571,299.37$ & 0.70 \\
\hline
\end{tabular}

Hence, VF $=461,357.97 / 562,631.67=0.82$

Further, it shows that for $600 \mathrm{~mm}$ diameter bores in the Project-A, VF is 0.85 while it is 0.75 for Project-B. Based on Table 5 the value of VF for more than $82 \%$ of the model output exceeds $75 \%$. This indicates that the model fits the cost of pile prediction for real world situation with $80 \%$ fitness.

\section{Discussion}

In this study, cost forecasting analysis was carried out in four stages, namely: review on previous studies; comprehensive questionnaire survey on local pile project experts; regression analysis on obtained data; and validation of model outputs with actual data to verify the developed cost forecasting models. The literature review shows that several studies have been carried out in various countries using different criteria.

Young [12] stated that there are three main factors which determine the selection of pile construction method: site environment, soil conditions, and economics of the construction method. In this study, the environmental factor has not been considered as the particular information is generally not available with the selected sample. Factors that affect drilling performance were identified by Peurifoy 
et al. [3], and Zayed and Halpin [10] as type of drill and size of bit; hardness of the soil; depth of holes; drilling pattern; terrain; and time lost waiting for other operations. If pneumatic drills are used, the rate of drilling varies with the pressure of the air. Another item that influences the rate of drilling is the machine availability factor. Furthermore, Harris [11] reported that there were two principal methods for drilling holes: (1) rotary or auger boring; and (2) conventional grabbing with a bucket. The selection of each type depends upon ground conditions, diameter and depth of borehole required, and the cost and availability of the equipment.

Peurifoy et al. [3], identified the factors that affect drilling, such as, type of drilling pile and size of auger, hardness of the soil, depth of holes, drilling pattern, and time consumption/waiting for other operations. The same result is revealed based on the importance level which is considered in this study.

In this study, the site interview results show adequate geotechnical data, concrete pouring time, actual piling project completion periods, rock socket length, depth of pile down to bedrock, and drilling time influence on cost of pilling. Furthermore, nine factors were identified but weather condition and geotechnical data were not included for regression analysis due to unavailability of the data.

CIEF [13] reports that piling construction practices with best performance not only provides increased market share and profitability but also brings many other intangible benefits such as visible brand name to the organization in the industry, quality in construction, employee motivation and satisfaction, improved customer satisfaction, and complements/awards from regulatory authorities.

Selected independent variables for the regression analysis are pile size, drilling time, depth of pile down to bedrock, rock socket length, concrete pouring time and type of machine. Zayed and Halpin [5], and Zayed [6] used regression technique to designate several regression models. Based on findings fifty-two regression models were designed to assess the piling process productivity and cycle time. These models have been validated to assure their appropriateness in the assessment process. The value of VF for more than $52 \%$ of the designated model outputs is approximately of $90 \%$ accuracy. Consequently, $83 \%$ of the model outputs have been predicted with more than $80 \%$ accuracy. In this study, $79 \%$ of designated model output is approximately of $80 \%$ accuracy. Hence this model can be considered to be appropriate enough to use in the local context.

\section{Conclusions and Recommendations}

From the data analysed, the study shows a positive and significant relationship between cost of pile and pile size, drilling time, depth of pile, concrete pouring time and rock socketing, while type of machine was found to be negatively and significantly related to piling cost. Rock socketing contributes to pile cost at a higher magnitude. The regression models achieved are liner statistical models, which enables convenience of cost prediction.

This overall cost model can be used if the identified six factor information are available. However, the matrix model (case model) will be useful when only limited data are available.

The value of VF for more than $77 \%$ of the model outputs reaches $75 \%$ fitness level with actual cost data, and justifies the reliability of these models to be used in practice. However, it should be emphasized that these models were developed based on $22 \%$ of actual piling contractor population and thus the developed models should be further re-evaluated with more data, which will be of mutually benefit to the industry as well as individual contractors.

\section{References}

1. Mullins, G. and Winters, D. (2014), "Defining the Upper Viscosity Limit for Mineral Slurries Used in Drilled Shaft Construction", University of South Florida, Department of Civil and Environmental Engineering.

2. Zayed, T. M. (2001), "Assessment of Productivity for Concrete Bored Pile Construction", Ph.D. Thesis submitted to School of Civil Engineering, Purdue University, West Lafayette, Indiana, USA, May.

3. Peurifoy, R. L., Ledbetter, W. L. and Schexnayder, C. J. (1996), "Construction, planning, equipment, and methods", 5th Ed., McGraw-Hill, New York. 
4. Lowe, D., Emsley, M. and Harding, A. (2006), "Predicting Construction Cost Using Multiple Regression Techniques", Journal of Construction Engineering and Management, ASCE, 132(7) $750-758$.

5. Zayed, T. M. and Halpin, D. W. (2001), "Construction Productivity Assessment Using Artificial Intelligence", Canadian Society for Civil Engineering Conference, Victoria, BC, Canada.

6. Zayed, T. M. (2001), "Productivity and Cost Regression Models for Pile Construction", Annual Conference of the Canadian Society for Civil Engineering.

7. Naoum, S. G (2007), "Dissertation Research and Writing for Construction Students", Oxford, UK: Elsevier Ltd. 2nd $\mathrm{Ed}$.

8. Neter, J., Michael H. K., Christopher N. and William W. (1996), “Applied Linear Statistical Models". McGraw-Hill, Boston.

9. Majid, M. Z. A. (1997), "Non-Excusable Delays in construction", Department of Civil and Building Engineering, Loughborough University, Leicestershire, UK. Ph.D Thesis.

10. Zayed, T. M. and Halpin, D. W. (2001), "Simulation of Bored Pile Construction", Winter Simulation Conference, Arlington, Virginia, IEEE Computer Society Washington, DC, USA.

11. Harris, F. (1983), "Ground Engineering Equipment and Methods", McGraw-Hill, New York.

12. Young, F. E. (1981), Piles and Foundations, Thomas Telford Limited, London.

13. CIEF (Construction Industry Environmental Forum) (2009), Joint CIEF and CPN seminar held at the Centre for Construction Innovation, CUBE, 113-115 Portland Street, Manchester M1 6DW. 